\section{The Role of Soluble Sugars in Vase Solutions during the Vase Life of Eustoma grandiflorum}

\author{
Ya-Ching Chuang and Yao-Chien Alex Chang ${ }^{1}$ \\ Department of Horticulture and Landscape Architecture, National Taiwan \\ University, 1 Roosevelt Road Sec. 4, Taipei 10617, Taiwan
}

Additional index words. cut flower, flower opening, flower senescence, sucrose, glucose, fructose

\begin{abstract}
The vase life of Eustoma cut flowers can be extended by adding sugars to the vase solution, but the exact role of sugars and how they are translocated in tissues are not clear. Thus, we observed the preserving effect of different sugars in vase solutions on Eustoma and compared sugar concentrations in vase solutions and in the flowers as well as stems and leaves of cut flowers in a solution containing $200 \mathrm{mg} \cdot \mathrm{L}^{-1} 8$-hydroxyquinoline sulfate (8-HQS) with and without $20 \mathrm{~g} \cdot \mathrm{L}^{-1}$ sucrose during different flowering stages. Inclusion of glucose, fructose, or sucrose in the vase solution extended the vase life of cut flowers with no significant differences among sugar types. During flower opening, the concentration of added sucrose in the vase solution dropped, and the fresh weight (FW), glucose concentration, and sucrose concentration of flowers in sucrose solutions increased, whereas flowers in solutions without sucrose had lower FW and glucose concentrations. During flower senescence, sugar concentration in the vase solution did not change much, but the FW and sucrose concentrations in all flowers declined, although the FW of sucrose-treated flowers fell more slowly. For stems and leaves in the sucrose solution, sugar concentrations increased during the first 7 days with only glucose slightly declining during senescence, whereas the $F W$ was maintained during the entire vase life. In contrast, FWs of those in the solution without sucrose gradually declined. In conclusion, sucrose in the vase solution promoted flower opening and maintained the water balance of Eustoma cut flowers. Glucose and fructose also extended the vase life, likely in similar ways.
\end{abstract}

Eustoma grandiflorum is a popular and important cut-flower crop as a result of its long, multiflowered inflorescence, and varying flower colors, sizes, and shapes. The vase life of Eustoma cut flowers can exceed 2 weeks under favorable conditions but is often cut short by early flower senescence or low opening rates of upper flower buds. Flower opening results from the rapid growth and enlargement of petal cells, which are in turn regulated by carbohydrate sources and the cell water potential (In et al., 2006; Pun and Ichimura, 2003). Flower senescence is accompanied by a drop in water uptake, petal wilting, flower abscission, and altogether lowered ornamental quality.

Sugars in vase solutions extend the vase life of many cut flowers including Eustoma (Cho et al., 2001; De la Riva et al., 2009; Ichimura and Korenaga, 1998; Islam et al., 2003). Carbohydrates are the main substrate

Received for publication 2 Nov. 2012. Accepted for publication 27 Dec. 2012.

Financial support was provided by the Agriculture and Food Agency, Council of Agriculture, Taiwan (102AS-9.2.2-FD-Z3).

This study is a part of the thesis submitted by Ya-Ching Chuang in partial fulfillment of Master of Science degree requirements.

${ }^{1}$ To whom reprint requests should be addressed; e-mail alexchang@ntu.edu.tw. stem; and like roses, leaves are usually retained on Eustoma cut flowers. Thus, sugar transport by Eustoma is more complex than that by the other two flowers, and more studies on Eustoma are needed. We tested the ability of Eustoma to take up and use different sugars in the vase solution and then investigated how the sugars were translocated by measuring sugar concentrations in different parts of Eustoma cut flowers with and without sugar-supplemented solutions.

\section{Materials and Methods}

\section{Plant materials}

Eustoma 'Ex Rosa Pink Flash' plants with five to seven buds were harvested when two or three of the buds had opened, immediately put in water, and sent to the laboratory. The vase-life evaluation began the day after harvest. Cut flowers were trimmed to $60 \mathrm{~cm}$ and leaves on the lower half of the stem were removed. The cut flowers were then placed in $450 \mathrm{~mL}$ of a vase solution maintained at 20 $\mu \mathrm{mol} \cdot \mathrm{m}^{-2} \cdot \mathrm{s}^{-1}$ with a 12 -h photoperiod, $25^{\circ} \mathrm{C}$, and a relative humidity of $60 \%$.

Expt. 1: Effects of different sugars and 8-hydroxyquinoline sulfate concentrations on vase life of Eustoma cut flowers. Vase lives of cut flowers in 10 different vase solutions were tested, including 100,200 , and $400 \mathrm{mg} \cdot \mathrm{L}^{-1}$ 8 -HQS; $20 \mathrm{~g} \cdot \mathrm{L}^{-1}$ sucrose, $20 \mathrm{~g} \cdot \mathrm{L}^{-1}$ fructose, or $20 \mathrm{~g} \cdot \mathrm{L}^{-1}$ glucose, alone or plus $200 \mathrm{mg} \cdot \mathrm{L}^{-1}$ 8-HQS; and distilled water as a control (Table 1). These concentrations were chosen according to previous literature (Ichimura and Korenaga, 1998; Islam et al., 2003) with a treatment each of higher and lower than normal (200 $\left.\mathrm{mg} \cdot \mathrm{L}^{-1}\right)$ 8-HQS concentration to evaluate if there are any toxic effects. All treatments consisted of eight replications. Vase life was considered to have ended when the number of open florets on a cut flower dropped below two.

Expt. 2: Sugar translocation during vase life of Eustoma cut flowers. Vase solutions containing $200 \mathrm{mg} \cdot \mathrm{L}^{-1} 8-\mathrm{HQS}$ or $20 \mathrm{~g} \cdot \mathrm{L}^{-1}$ sucrose plus $200 \mathrm{mg} \cdot \mathrm{L}^{-1}$ 8-HQS were made with milliQ water (Millipore, Billerica, MA). The rims of the containers were sealed with parafilm (American National Can, Greenwich, CT) to prevent evaporation. In this experiment, we kept a uniform number of 12 leaves remaining on each cut flower. On Days $0,7,14$, and 21 in the vase, eight cut flowers were taken and separated into two parts: flowers and leaves/stem. Plant parts were weighed and freeze-dried, and sugar concentrations were measured according to methods of Hou et al. (2011). Freeze-dried plant parts were ground to powder, and $50 \mathrm{mg}$ of each sample was extracted at $70{ }^{\circ} \mathrm{C}$ with $3 \mathrm{~mL} 80 \%$ ethanol for $30 \mathrm{~min}$. One milligram of raffinose was added to each sample as the internal standard. After extraction, the tissue suspension was centrifuged at $4000 g_{n}$ for $10 \mathrm{~min}$ to collect the supernatant. Each sample was again extracted twice, and the three supernatants were pooled together. The pooled supernatants were deionized by passage through columns with $1 \mathrm{~mL}$ cation resin 
Table 1. Effects of sugars and 8-hydroxyquinoline sulfate (8-HQS) in the vase solution on the vase life of Eustoma 'Ex Rosa Pink Flash' cut flowers.

\begin{tabular}{lc}
\hline Vase solution & $\begin{array}{c}\text { Vase } \\
\text { life }(\mathrm{d})\end{array}$ \\
\hline $\mathrm{H}_{2} \mathrm{O}$ & $13.4 \mathrm{c}^{\mathrm{z}}$ \\
$100 \mathrm{mg} \cdot \mathrm{L}^{-1}$ 8-HQS & $12.9 \mathrm{c}$ \\
$200 \mathrm{mg} \cdot \mathrm{L}^{-1}$ 8-HQS & $12.4 \mathrm{c}$ \\
$400 \mathrm{mg} \cdot \mathrm{L}^{-1}$ 8-HQS & $11.5 \mathrm{c}$ \\
$20 \mathrm{~g} \cdot \mathrm{L}^{-1}$ glucose & $17.4 \mathrm{ab}$ \\
$20 \mathrm{~g} \cdot \mathrm{L}^{-1}$ fructose & $16.6 \mathrm{~b}$ \\
$20 \mathrm{~g} \cdot \mathrm{L}^{-1}$ sucrose & $19.0 \mathrm{ab}$ \\
$20 \mathrm{~g} \cdot \mathrm{L}^{-1}$ glucose $+200 \mathrm{mg} \cdot \mathrm{L}^{-1} 8-\mathrm{HQS}$ & $19.6 \mathrm{a}$ \\
$20 \mathrm{~g} \cdot \mathrm{L}^{-1}$ fructose $+200 \mathrm{mg} \cdot \mathrm{L}^{-1}$ 8-HQS & $19.4 \mathrm{a}$ \\
$20 \mathrm{~g} \cdot \mathrm{L}^{-1}$ sucrose $+200 \mathrm{mg} \cdot \mathrm{L}^{-1} 8-\mathrm{HQS}$ & $18.8 \mathrm{ab}$ \\
Analysis of variance test for $P$ value & \\
$8-\mathrm{HQS}$ & 0.2791 \\
Sugar & $<0.0001$ \\
$8-\mathrm{HQS} \times$ sugar & 0.1090 \\
\hline
\end{tabular}

${ }^{\mathrm{z}}$ Means in the same column followed by different letters significantly differ at $P \leq 0.05$ by the least significant difference test; $\mathrm{n}=8$.

(Dowex-50W, hydrogen form; Sigma, St. Louis, MO) and $1 \mathrm{~mL}$ anion resin (Amberlite IRA-167, acetate form; Sigma). Samples were then reduced in volume in a vacuum concentrator (Rapidvap Vacuum Evaporation System; Labconco, Kansas City, MO) to less than $1 \mathrm{~mL}$ and diluted to $10 \mathrm{~mL}$ with MilliQ water. After filtration $(0.22 \mathrm{~mm})$ and appropriate dilutions, samples were subjected to high-performance anion exchange chromatography (Dionex, Sunnyvale, CA) with pulsed amperometric detection (ED50; Dionex) equipped with a Carbopac PA-1 column (CarboPac ${ }^{\mathrm{TM}}$ PA1 Analytical, $4 \times$ $250 \mathrm{~mm}$; Dionex). Carbohydrates were eluted with $100 \mathrm{~mm} \mathrm{NaOH}$ at a flow rate of $1 \mathrm{~mL} \cdot \mathrm{min}^{-1}$ for $20 \mathrm{~min}$. The separated carbohydrates (glucose, fructose, and sucrose) were quantified by comparison with known standards.

Vase solutions of sampled flowers were also taken at the same time and stored at $-20{ }^{\circ} \mathrm{C}$ until being analyzed. Solutions were filtered, diluted 1000 times, and subjected to high-performance anion exchange chromatography at the described conditions.

\section{Statistical analysis}

Data were subjected to an analysis of variance using a completely randomized design. Separation of means between treatments was determined with Fisher's protected least significant difference test at $P \leq 0.05$. Statistical analyses were performed with SAS 9.0 (SAS Institute, Cary, NC).

\section{Results}

In Expt. 1, the addition of 100 to 400 $\mathrm{mg} \cdot \mathrm{L}^{-1} 8$-HQS to the vase solution did not affect the vase life of Eustoma 'Ex Rosa Pink Flash' cut flowers (Table 1). The addition of $20 \mathrm{~g} \cdot \mathrm{L}^{-1}$ sucrose, fructose, or glucose lengthened vase life by 3 to $6 \mathrm{~d}$. The fructose solution showed a better preservation capability when used in the presence of 8-HQS, but the vase life of flowers in sucrose solutions averaged $19 \mathrm{~d}$ regardless of whether

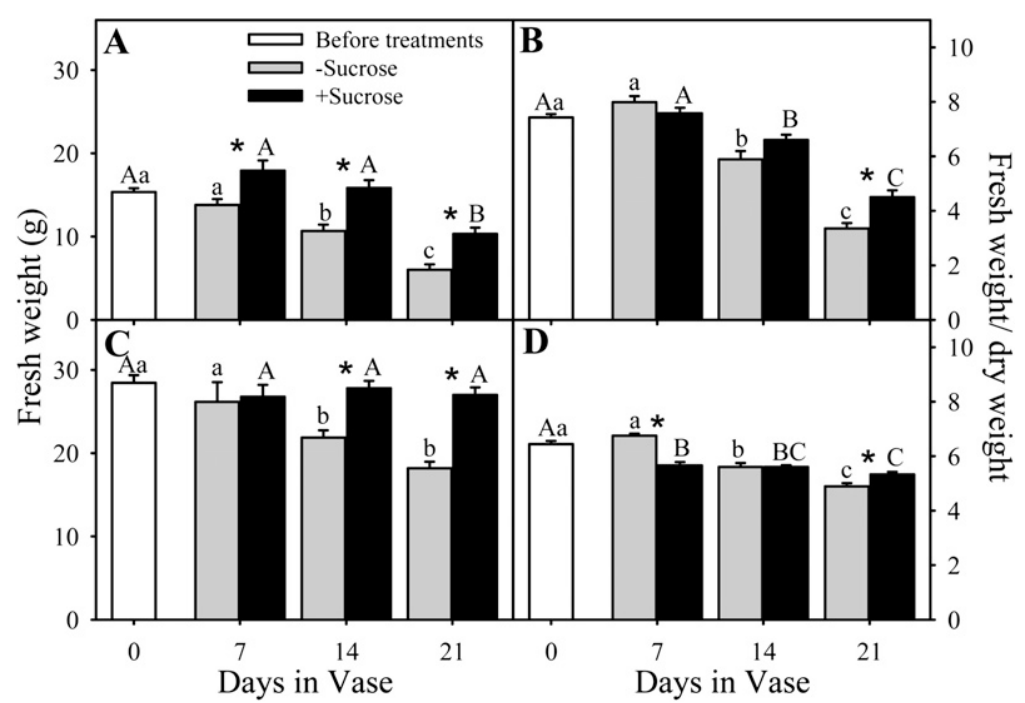

Fig. 1. Fresh weight $(\mathbf{A}, \mathbf{C})$ and fresh weight/dry weight ratio $(\mathbf{B}, \mathbf{D})$ of flowers $(\mathbf{A}-\mathbf{B})$ and the stem and leaves (C-D) of Eustoma 'Ex Rosa Pink Flash' at 0, 7, 14, and $21 \mathrm{~d}$ in vase solutions with (+sucrose) or without (-sucrose) $20 \mathrm{~g} \cdot \mathrm{L}^{-1}$ sucrose. All vase solutions contained $200 \mathrm{mg} \cdot \mathrm{L}^{-1} 8$-HQS. Means at the different days with different letters significantly differ by the least significant difference test at $P \leq$ 0.05; upper case, +sucrose treatment; lowercase, -sucrose treatment. Significance within treatments on the same day is indicated by an asterisk $(*)$. Bars indicate the sE; $\mathrm{n}=8.8$-HQS $=8$-hydroxyquinoline sulfate.

8-HQS was added. Thus, for Expt. 2, we chose $200 \mathrm{mg} \cdot \mathrm{L}^{-1} \quad 8-\mathrm{HQS}$ and $20 \mathrm{~g} \cdot \mathrm{L}^{-1}$ sucrose plus $200 \mathrm{mg} \cdot \mathrm{L}^{-1} 8$-HQS as the respective no-sugar and with-sugar treatments. Sucrose in vase solutions promoted flower opening such that all buds on the inflorescences opened within $7 \mathrm{~d}$ in the vase, whereas buds in the solution without sucrose did not fully open throughout $21 \mathrm{~d}$ in the vase. Flower wilting rate was also slower for those in the sucrose-treated group, thus resulting in longer cut-flower vase life (data not shown).

On Day 0 in the vase, the flower FW was $15.4 \mathrm{~g}$ (Fig. 1A), and the FW/dry weight (DW) ratio was 7.4 (Fig. 1B). By Day 7 in the vase, the FW of flowers in the sucrose solution had risen to $17.9 \mathrm{~g}$, whereas the FW of flowers in the solution without sucrose was slightly lower than that on Day 0; the FW/ DW ratios of flowers were consistent between Days 0 and 7 regardless of treatment. After Day 7, flowers in both treatments began to lose FW with a significant difference by Day 14 for flowers without sucrose treatment and Day 21 for the sucrose-treated group. The DW of flowers was constant during Days 7 to 21 for both treatments (data not shown), thus indicating water loss as the main cause of FW loss. The FW/DW ratios of flowers gradually declined during flower wilting, but this was more severe for flowers in the solution without sucrose than those in the sucrosecontaining solution.

The FW of the leaves and stem was $28.5 \mathrm{~g}$ on Day 0 (Fig. 1C), and the FW/DW ratio was 6.4, slightly lower than that of flowers (Figs. $1 \mathrm{~B}$ and 1D). No difference was detected in FWs of leaves and the stem during the entire $21 \mathrm{~d}$ in sucrose-solution treatment. Leaf and stem FWs of cut flowers in the solution without sucrose, however, declined with time and were only $18.2 \mathrm{~g}$ by Day 21 (Fig. 1C). By Day 7 in the vase, the leaves and stem in the sucrose solution had accumulated DW (data not shown) and thus the FW/DW ratio had dropped to 5.7, whereas in the solution without sucrose, the FW/DW ratio had risen to 6.8 (Fig. 1D), indicating a higher DW loss to FW loss rate in the group without sucrose treatment. Similar to that of flowers, the FW/ DW ratio of the leaves and stem in both treatments gradually declined from Days 7 to 21 , and the decrease was more notable in the solution without sucrose than in the sucrose group. By Day 21, leaves of cut flowers in the solution without sucrose were notably wilted, and the FW/DW ratio had dropped to 4.9 , significantly lower than that in the sucrose solution. The FW/DW ratio of the leaves and stem at Day 21 in the sucrose solution was 5.3, not much lower than either treatment group at Day 14 (Fig. 1D).

A low concentration of $0.04 \mathrm{~g} \cdot \mathrm{L}^{-1}$ sucrose was detected in the solution without sucrose. The concentration continued to decline during cut-flower evaluation and dropped to $0.01 \mathrm{~g} \cdot \mathrm{L}^{-1}$ by Day 21 (Fig. 2C). Glucose and fructose concentrations were 0.05 and $0.3 \mathrm{~g} \cdot \mathrm{L}^{-1}$ on Day 0 , respectively, and both dropped to $0.01 \mathrm{~g} \cdot \mathrm{L}^{-1}$ by Day 7 (Fig. 2A-B). The sucrose concentration in the sucrose vase solution dropped from 22.0 to $16.7 \mathrm{~g} \cdot \mathrm{L}^{-1}$ within $7 \mathrm{~d}$ in the vase but fell no lower after that. The glucose concentration in the sucrose vase solution remained constant at $0.2 \mathrm{~g} \cdot \mathrm{L}^{-1}$ for the entire $21 \mathrm{~d}$. The fructose concentration, however, did not fall but rose from 0.2 to $0.7 \mathrm{~g} \cdot \mathrm{L}^{-1}$ during cut-flower evaluation.

The most abundant sugar in Eustoma flowers was glucose, amounting to $7.8 \%$ of the DW on Day 0 in the vase. Next was sucrose at $2.9 \%$ of the DW and fructose at 


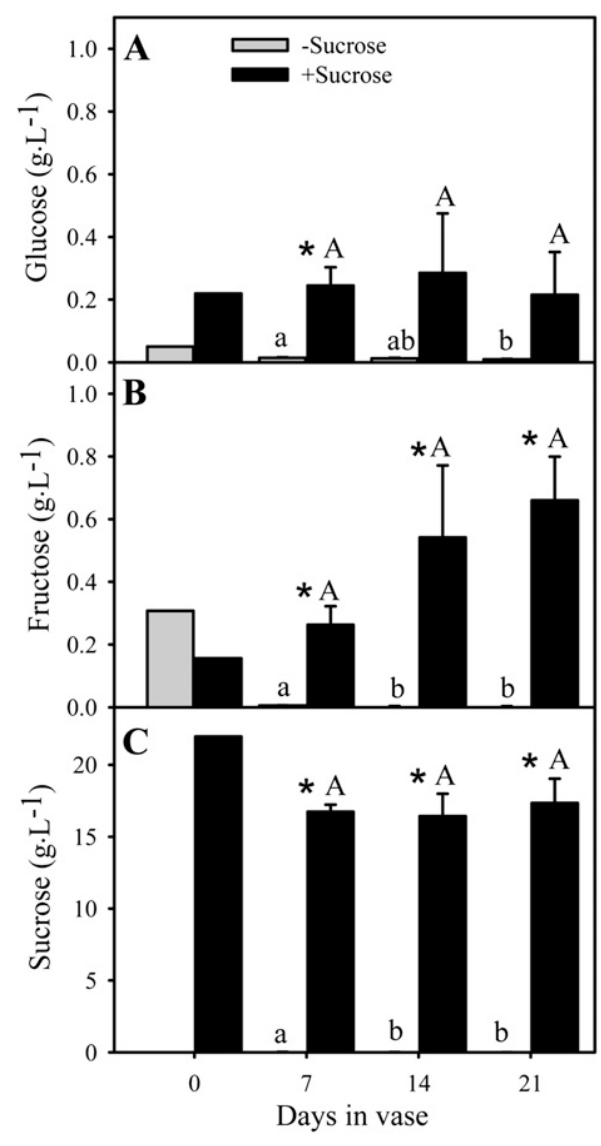

Fig. 2. Changes of glucose (A), fructose (B), and sucrose $(\mathbf{C})$ concentrations in vase solutions containing Eustoma 'Ex Rosa Pink Flash' cut flowers for $0,7,14$, and $21 \mathrm{~d}$. The treated group (+sucrose) was supplemented with $20 \mathrm{~g} \cdot \mathrm{L}^{-1}$ sucrose, whereas the control (-sucrose) was not; both treatments contained $200 \mathrm{mg} \cdot \mathrm{L}^{-1}$ 8-HQS. Means at the different days with different letters significantly differ by the least significant difference test at $P \leq 0.05$; upper case, +sucrose treatment; lowercase, -sucrose treatment. Significance within treatments on the same day is indicated by an asterisk (*). Bars indicate the SE; $\mathrm{n}=8$ for Days 7, 14, and $21 ; \mathrm{n}=1$ for Day 0. 8-HQS = 8-hydroxyquinoline sulfate.

$0.9 \%$ of the DW (Figs. 3A, 3C, and 3E). In the leaves and stem, glucose and sucrose concentrations were similar, respectively accounting for $0.8 \%$ and $0.9 \%$ of the DW. The fructose concentration, at $0.1 \%$ of the DW, was the lowest of the three sugars (Figs. 3B, $3 \mathrm{D}$, and $3 \mathrm{~F}$ ). After $7 \mathrm{~d}$ in the vase solution without sucrose, both glucose and sucrose concentrations in the flowers had dropped to less than half of the initial level. During Days 7 to 14 , glucose and sucrose concentrations continued to fall but at a rate lower than that in the first $7 \mathrm{~d}$. The fructose concentration did not begin to drop until after Day 7. During Days 14 to 21, none of the three sugar concentrations significantly changed (Figs. $3 \mathrm{~A}, 3 \mathrm{C}$, and $3 \mathrm{E})$. In the leaves and stem, glucose and fructose concentrations remained constant, whereas sucrose concentrations continually decreased for the entire $21 \mathrm{~d}$ (Figs. 3B, $3 \mathrm{D}$, and $3 \mathrm{~F}$ ). When sucrose was added to the

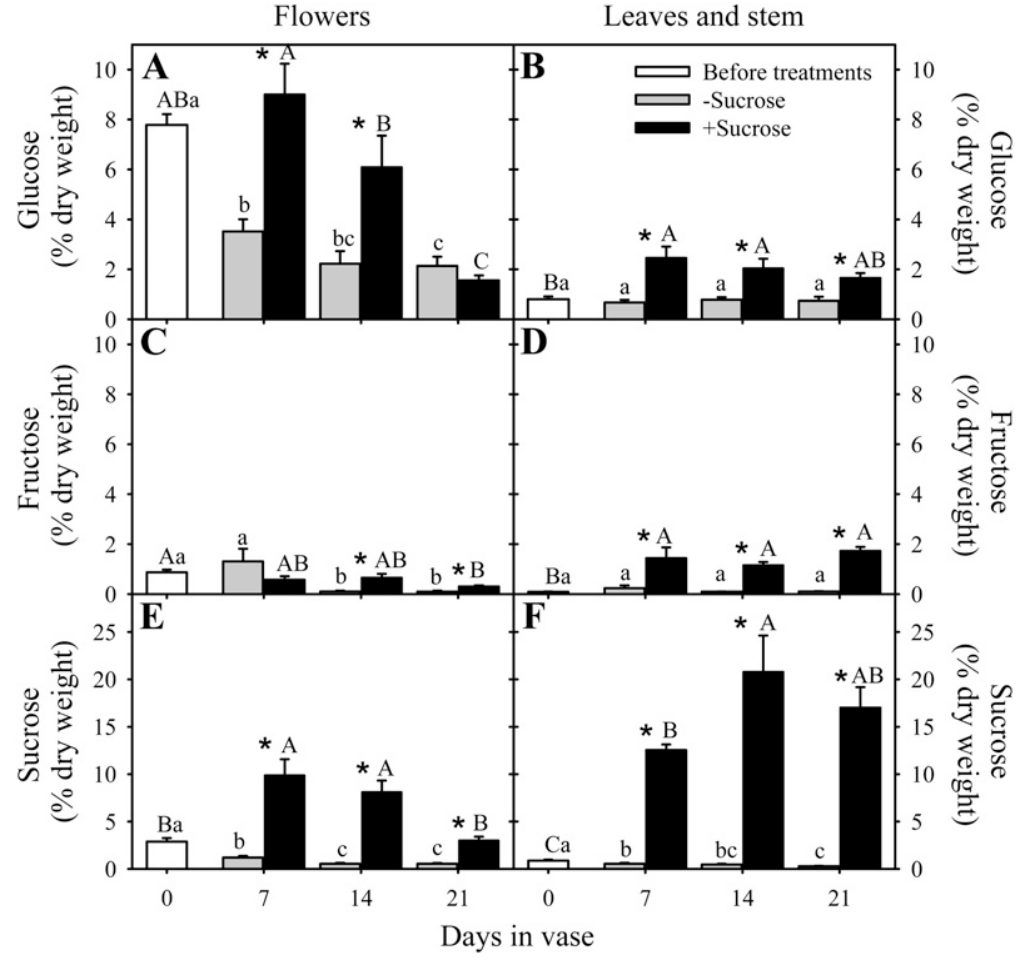

Fig. 3. Changes of glucose (A-B), fructose $(\mathbf{C}-\mathbf{D})$, and sucrose $(\mathbf{E}-\mathbf{F})$ concentrations in Eustoma 'Ex Rosa Pink Flash' flowers (A, C, E) and leaves and stem (B, D, F) after 0, 7, 14, and $21 \mathrm{~d}$ in vase solutions with (+sucrose) or without (-sucrose) $20 \mathrm{~g} \cdot \mathrm{L}^{-1}$ sucrose. All vase solutions contained $200 \mathrm{mg} \cdot \mathrm{L}^{-1}$ 8 -HQS. Means at the different days with different letters significantly differ by the least significant difference test at $P \leq 0.05$; upper case, +sucrose treatment; lowercase, -sucrose treatment. Significance within treatments on the same day is indicated by an asterisk (*). Bars indicate the SE; $\mathrm{n}=8.8$-HQS $=8$-hydroxyquinoline sulfate.

vase solution, the sucrose concentration in flowers rose over 3 -fold in $7 \mathrm{~d}$. Afterward the sucrose concentration declined but even by Day 21 had not dropped lower than the initial level (Fig. 3E). The glucose concentration did not change during the first $7 \mathrm{~d}$ but began to fall during Days 7 to 14 and decreased much faster during Days 14 to 21; therefore, on Day 21, the glucose concentration in sucrose-treated flowers was lower than that in the group without sucrose (Fig. 3A). The fructose concentration did not change much, remaining constant from Days 7 to 21 (Fig. 3C). In the leaves and stem, all three sugars showed increased concentrations when cut flowers were kept in a sucrose solution for $7 \mathrm{~d}$. Afterward, sucrose further accumulated until Day 14, whereas no further change was detected in the glucose or fructose concentrations of the leaves and stem (Figs. 3B, 3D, and 3F).

\section{Discussion}

The vase life of Eustoma cut flowers was significantly lengthened by the addition of $20 \mathrm{~g} \cdot \mathrm{L}^{-1}$ of sucrose, fructose, or glucose to the vase solution (Table 1), demonstrating the ability of Eustoma flowers to take up and use all three sugars. Addition of 100 to $400 \mathrm{mg} \cdot \mathrm{L}^{-1} 8$-HQS did not affect the vase life. Because the main function of 8 -HQS in vase solutions is to prevent bacterial growth and vascular occlusion (Ichimura et al., 1999), its effects may be greatly influenced by harvesting and evaluation conditions; in this case, bacterial growth did not seem to be an important limiting factor of vase life, yet $200 \mathrm{mg} \cdot \mathrm{L}^{-1} 8$-HQS did extend the vase life of flowers in a fructose solution, whereas no significant improvements resulting from 8-HQS were observed in cut flowers in the sucrose or glucose solutions (Table 1). Fructose might be a more preferred sugar source for those bacteria that cause Eustoma vascular occlusion. It is also possible that Eustoma does not take up fructose as readily as it does glucose or sucrose, whereas the presence of 8 -HQS aids in vascular transportation. This discrimination of form observed in uptake was not extended to sugar use, because the vase life of cut flowers in the fructose + 8 -HQS solution was the same as that in glucose +8 -HQS. Conversion of fructose to glucose may have occurred in flower tissues, resulting in lower fructose and higher glucose concentrations throughout the vase life (Figs. 3A and 3C).

The drop in the sucrose concentration in the vase solution during the first $7 \mathrm{~d}$ in the vase suggests a higher sucrose uptake compared with water uptake rate (Fig. 2C). The low concentrations of glucose and fructose in sucrose-containing vase solutions may have originated from the decomposition of dissolved sucrose, because they remained at a relatively low constant level during the entire experimental period (Fig. 2A-B). In 
contrast, small amounts of sugars originally present in the vase solution without sucrose decreased to very low levels after Day 7, showing that $0.01 \mathrm{~g} \cdot \mathrm{L}^{-1}$ sugar, although not necessarily enough to extend the vase life of cut flowers, was used by the cut flower.

The period of Days 0 to 7 was the time when over $90 \%$ of flower opening occurred (data not shown), during which both sucrose and glucose concentrations of flowers in solution without sucrose dropped to low levels (Figs. 3A and 3E). Because flower opening requires energy, sucrose decomposition and glucose consumption could reasonably account for the decrease. When a plant's internal sucrose supply is limited, external sucrose may be brought in for use, prompting a higher flower opening rate of Eustoma cut flowers, as our results again confirmed those previously reported in the literature (Cho et al., 2001; De la Riva et al., 2009; Ichimura and Korenaga, 1998). Sucrose concentrations in plant tissues of sucrosetreated cut flowers rose during the first $7 \mathrm{~d}$ in the vase (Fig. 3E-F), corresponding to a drop in the concentration in the vase solution (Fig. 2C). Glucose concentrations also rose in the leaves and stem during the first $7 \mathrm{~d}$ (Fig. 3B) but remained constant in the flowers, where it was originally the sugar with the highest concentration (Figs. 3A, 3C, and $3 \mathrm{E}$ ). In fact, on Day 0 , the glucose concentration in flowers was highest among all sugar forms and plant parts. Therefore, this lack of increase in glucose concentration in flowers was not because it was not needed, but because it was already saturated. Flowers are a major carbohydrate sink during cutflower opening (Waithaka et al., 2001), and glucose, as the most directly usable form, would be quickly metabolized rather than conserved. Previous literature reported Eustoma flowers have a longer life when placed in $1 \%$ glucose than in sucrose solution (Cho et al., 2001). We did not observe this situation, probably because the higher concentration of sugars we used had better preserving effects and hence showed less pronounced differences between types. The leaves and stem, in contrast, are weaker sinks (Marissen and La Brijn, 1995), and accumulation of glucose will occur only when supplies are abundant. Sucrose accumulation in all plant parts shows that it is readily transported and is not converted into hexoses until needed, thus acting as a temporary storage carbohydrate (Fig. 3E-F).

Sucrose concentrations in Eustoma stems and leaves during vase life were directly influenced by the vase solution, rising when sucrose was added and dropping when sucrose was not added (Fig. 3F). This indicates that sucrose is stored in the leaves and stem and possibly transported to flowers when needed. Carbohydrates used for flower opening of roses were shown to be transported from leaves on the cut flowers (Marissen and La Brijn, 1995). In the leaves and stems of Eustoma cut flowers, sucrose concentration decreased when no sucrose was added to the vase solution, yet glucose concentrations did not decrease much with time, even when cut flowers were in a solution without sucrose (Fig. 3B). Thus, at least some sucrose is likely consumed by the basic metabolism of the leaves and stem themselves.

During Days 14 to 21, regardless of whether sucrose was initially added, no decrease in sugar concentrations was detected in the vase solutions (Fig. 2), indicating that an external carbohydrate supply was no longer greatly needed, and the plant water potential was in dynamic balance with the vase solution, resulting in more or less equivalent uptake of water and sucrose. That opening flowers are main carbohydrate sinks and senescent ones weaker sinks is in accordance with studies on gladiolus, in which carbohydrates are translocated from lower senescent florets to upper opening florets (Waithaka et al., 2001). The fructose concentration actually slightly increased in sucroseadded solutions from Day 7 to Day 21 (Fig. 2B), further suggesting that fructose is a lessfavored sugar source, especially when glucose is present. In flowers of the group with sucrose addition, the glucose concentration was significantly reduced by Day 14 and more so by Day 21, whereas the fructose concentration remained nearly constant from Days 7 to 21 (Figs. 3A and 3C). It should be emphasized again that although use of glucose is preferred, fructose is also serviceable for Eustoma, as evidenced in its decrease between Days 7 and 14 in flowers without sugar treatment (Fig. 3C).

Alongside symptoms of flower senescence, sugar concentrations in flowers decreased after Day 7 (Figs. 3A, 3C, and 3E). In the group without sucrose addition, this decrease ended by Day 14, when more than $75 \%$ of flowers had already wilted (data not shown), yet the glucose concentration at this point was not as low as that of Day 21 flowers in the sucrose-containing group (Fig. 3A), so it did not seem to be the limiting factor causing flower wilting. Because the vase life had nearly ended, these flowers simply no longer required sugar for metabolism. In flowers of the sucrose-containing group, glucose was gradually consumed until a low concentration was reached (Fig. 3A), but sucrose did not drop below the initial concentration during the entire 21-d period (Fig. $3 \mathrm{E})$. Hence, the main preserving effect of sugars on flowers after flower opening is unlikely attributable to providing an energy source, but perhaps to act as water solutes for maintaining the water potential. Higher flower FW/DW ratios during Days 7 to 21 support the assumption that flowers placed in a sucrose solution had a better waterconserving capacity (Fig. 1B). Previous reports showed that Eustoma is ethylene-sensitive (Ichimura et al., 1998), and pulse treatment with $40 \mathrm{~g} \cdot \mathrm{L}^{-1}$ sucrose effectively lowered its ethylene production rate (Huang and Chen, 2002). We did not measure ethylene production in this study, but according to reported results on Delphinium and sweet pea (Lathyrus odoratus L.) flowers (Pun and Ichimura, 2003), it is possible that sucrose in the vase solution might also protect Eustoma flowers against ethylene-induced senescence.

Sucrose concentrations of the stem and leaves in the solution without sucrose gradually decreased with time as did that in flowers (Fig. 3E-F). Sucrose concentrations of the stem and leaves in the sucrose-containing solution, however, continued to increase until Day 14, 1 week after all flowers had opened. Because Eustoma is naturally a perennial, excess carbohydrates can be stored in vegetative organs for future use, and sucrose in flowers, in addition to being consumed as energy, might possibly be transported back to the leaves and stem, hence resulting in the large drop in the sucrose concentration on Day 21 (Fig. 3E). Previous articles reported that leaf injury to Eustoma cut flowers treated with sucrose pulsing or vase solution is caused by excessive sucrose absorption, especially under low relative humidity conditions (ShimizuYumoto and Ichimura, 2007, 2009). No such phenomenon was noted in our studies, and sucrose-treated cut flowers had better longevity of both flowers and leaves than those without sucrose treatment.

Sugars in the vase solution were repeatedly shown to have beneficial effects on cutflower quality of Eustoma (Cho et al., 2001; Islam et al., 2003). During flower opening, sucrose is transported to flowers and converted to hexoses as energy sources and to maintain the water potential. Fructose can be used, but glucose is preferred. When in surplus, sucrose is stored in flowers as a water solute and perhaps as an ethylene inhibitor; but ultimately sucrose stops entering, and all sugar concentrations drop with flower senescence. Leaves and stems are able to accumulate sucrose present in the vase solution, regardless of flower development, and sucrose is possibly transported back to the leaves when the flowers wilt.

\section{Literature Cited}

Cho, M.S., F.G. Celikel, L. Dodge, and M.S. Reid. 2001. Sucrose enhances the postharvest quality of cut flowers of Eustoma grandiflorum (Raf.) Shinn. Acta Hort. 543:305-315.

De la Riva, F., P.C. Mazuela, J.E. Álvaro, and M. Urrestarazu. 2009. Treatment with peracetic acid extends the vase life of lisianthus (Eustoma grandiflorum) flowers. HortScience 44:418-420.

Hou, J.Y., W.B. Miller, and Y.C.A. Chang. 2011. Effects of simulated dark shipping on the carbohydrate status and post-shipping performance of Phalaenopsis. J. Amer. Soc. Hort. Sci. 136:364-371

Huang, K.L. and W.S. Chen. 2002. BA and sucrose increase vase life of cut Eustoma flowers. HortScience 37:547-549.

Ichimura, K., K. Kojima, and R. Goto. 1999. Effects of temperature, 8-hydroxyquinoline sulphate and sucrose on the vase life of cut rose flowers. Postharvest Biol. Technol. 15: 33-40.

Ichimura, K. and M. Korenaga. 1998. Improvement of vase life and petal color expression in several cultivars of cut Eustoma flowers using sucrose with 8-hydroxyquinoline sulfate. Bul. Natl. Res. Inst. Veg. Ornamental Plants Tea 13:31-39. 
Ichimura, K., M. Shimamura, and T. Hisamatsu. 1998. Role of ethylene in senescence of cut Eustoma flowers. Postharvest Biol. Technol. 14:193-198.

In, B.C., K. Sato, K. Ito, K. Inamoto, M. Doi, and G. Mori. 2006. Influences of preharvest relative humidity on yield, vase life and transpiration of cut roses. J. Environ. Control Biol. 44:257-263.

Islam, N., G.G. Patil, and H.R. Gislerød. 2003. Effects of pre- and postharvest conditions on vase life of Eustoma grandiflorum (Raf.) Shinn. Europ. J. Hort. Sci. 68:272-278.
Marissen, N. and L. La Brijn. 1995. Source-sink relations in cut roses during vase life. Acta Hort. 405:81-88.

Mayak, S., S. Meir, and H. Ben-Sade. 2001. The effect of transient water stress on sugar metabolism and development of cut flowers. Acta Hort. 543:191-198.

Pun, U.K. and K. Ichimura. 2003. Role of sugars in senescence and biosynthesis of ethylene in cut flowers. Jpn. Agr. Res. Qrtly. 37:219-224.

Shimizu-Yumoto, H. and K. Ichimura. 2007. Effect of relative humidity and sucrose concentration on leaf injury and vase life during sucrose pulse treatment in cut Eustoma flowers. Hort. Res. (Japan) 6:301-305.

Shimizu-Yumoto, H. and K. Ichimura. 2009. Abscisic acid, in combination with sucrose, is effective as a pulse treatment to suppress leaf damage and extend foliage vase-life in cut Eustoma flowers. J. Hort. Sci. Biotechnol. 84:107-111.

Waithaka, K., L.L. Dodge, and M.S. Reid. 2001. Carbohydrate traffic during opening of gladiolus florets. Acta Hort. 543:217-226. 